\title{
La Tribuna: Drama Musical en Tres Actos: música de Gabriel Bussi, libretto de Javier Ozores Marchesi, basado en la novela de Emilia Pardo Bazán La Tribuna
}

\author{
Gabriel Bussi \\ gabrielbussi@gmail.com \\ Javier Ozores Marchesi \\ jozores2@telefonica.net
}

(recibido outubro/2017, revisado decembro/2017)

RESUMEN: Presentación de la ópera La Tribuna, y publicación de su libretto, adaptación de la novela homónima de Emilia Pardo Bazán. La música fue compuesta por Gabriel Bussi y el libretto por Javier Ozores Marchesi.

PALABRAS ClAVE: La Tribuna, Emilia Pardo Bazán, Javier Ozores Marchesi, Gabriel Bussi, ópera.

ABSTRACT: Presentation of La Tribuna opera, and publication of his libretto. Adaptation of the homonymous novel of Emilia Pardo Bazán. The music was composed Gabriel Bussi and the libretto by Javier Ozores Marchesi.

KEY WORDS: La Tribuna, Emilia Pardo Bazán, Javier Ozores Marchesi, Gabriel Bussi, ópera.

La obra se basa en la célebre novela La Tribuna (1882) de la escritora coruñesa Emilia Pardo Bazán, que destaca por ser la primera manifestación de tendencia naturalista literaria en nuestro país. Ambientada en A Coruña, a la que Ilama Marineda, su acción transcurre en los convulsos años previos a la implantación de la República Federal y nos presenta el mundo del proletariado y de la actividad laboral representada por la Fábrica de Tabacos donde trabaja Amparo, la protagonista, enfrentada al mundo burgués representado por su amante Baltasar.

Aunque la historia en sí es ficcional, la autora retrató fielmente la vida fabril de las cigarreras y se sirvió de una destacada cigarrera que conocía para describir el personaje de Amparo. Además, los acontecimientos reflejan los eventos y las condiciones verdaderas de A Coruña en concreto y España en general, constituyendo así un verdadero retrato social de la época en cuestión.

En la siguiente sinopsis comentada, todos los pasajes en cursiva son citas literales del libreto de ópera de Javier Ozores Marchesi, que adaptó la complejidad de la novela 
original a los requerimientos operísticos, unificando y omitiendo escenas y personajes, además de poner el texto en versos, siempre manteniendo la esencia del original literario.

\section{ACTO /}

El primer acto es, con sus 60 minutos de duración, el más extenso de los tres. Presenta a los personajes en el prólogo, donde además ya se describen las relaciones entre ellos, incluyendo el amor frustrado de Chinto por Amparo, así como una primera toma de contacto entre Amparo y su futuro amante Baltasar. En las siguientes escenas se hace más hincapié en los eventos sociopolíticos, acercándonos a la vida cotidiana de las cigarreras y a una reunión de los bandos revolucionarios, donde Amparo es nombrada La Tribuna del pueblo, gracias a su carisma y sus dotes de liderazgo.

\section{Acto I, Prólogo.}

La escena representa la fachada principal de la Fábrica de Tabacos de Marineda. La tarde, que amenaza Iluvia, no invita al paseo. Esta escena, apoyándose en el dramatismo creado por el tiempo adverso, es retratada musicalmente en una obertura instrumental, que enlaza con la primera intervención de los cantantes. Chinto, un joven aldeano que trabaja como jornalero para el barquillero Rosendo, el padre de Amparo, está vendiendo barquillos delante de la verja de la fábrica. Rosendo, él mismo viviendo en condiciones de miseria, le reprende, porque está deambulando en zonas de poca afluencia donde las ventas no pueden ser muy sustanciales. La verdad es que Chinto busca la cercanía de Amparo, de la cual está perdidamente enamorado, aun siendo despreciado por ella, y se acerca la hora de salida de las cigarreras, entre las cuales se encuentra su amor. En una gran aria romántica (Cuántos colores), Chinto le confía su profundo dolor al mar.

Suena la sirena de salida de la fábrica, y Amparo sale junta a su amiga y confidente Ana, un personaje que también aparece en el original literario, pero que en la ópera es potenciado, porque amalgama una variedad de protagonistas que no tenían cabida en el marco de una ópera. Amparo lamenta que Chinto la esté constantemente acechando. Borrel, amigo de Baltasar, un joven oficial, le llama la atención a este sobre los esplendores de Amparo, y le incita a interesarse por ella.

Este Prólogo concluye con un elemento muy atípico del género, una escena de enamoramiento de cuatro minutos puramente sinfónica, con los cantantes actuando sin cantar, en la cual las miradas de Amparo y Baltasar se cruzan, y ante la insistencia molesta de Chinto por ofrecerle un melocotón a Amparo, esta lo coge con desprecio, y se lo tira a Baltasar, quedando los dos mirándose fijamente.

\section{Acto I, Esc. 1 ${ }^{\mathrm{a}}$}

Después del Prólogo dramático, esta escena le da un toque buffo a la ópera, describiendo la vida de las cigarreras en la fábrica: Interior de la Fábrica de Tabacos. Un grupo de operarias está trabajando en la confección del tabaco. Entre ellas está Amparo, en el centro, leyéndoles un periódico. 
Amparo es la única de las cigarreras que sabe leer, y por tanto es la elegida para amenizar la jornada, leyéndoles a sus compañeras noticias de revistas revolucionarias. Ellas, en cambio le recompensan por el tiempo y dinero perdido. La situación política es muy crítica, y se siente una notable crispación de las cigarreras, quienes se dejan llevar por el tono revolucionario de la prensa, atacando el statu quo y desacreditando las clases sociales superiores, así como los cuerpos oficiales del gobierno. Amparo recita los artículos de prensa con convencida e ingenua teatralidad, mostrando sus dotes de liderazgo con carisma intrépido y acalorado. La música oscila entre bailes con tono popular y escenas lúgubres, aunque siempre con un toque satírico, acompañando los cambios expresivos en la recitación de Amparo.

Cuando Ilega la hora del almuerzo, se quedan Amparo y Ana solas, ocasión que esta aprovecha (Dúo: Vi esta mañana) para advertirle a Amparo que no se meta con Baltasar, por lo inviable que resultaría esa relación. Amparo se resiste a aceptar la advertencia. Al insinuar Ana a su amiga que aún tiene otro obsequiante, implicando así que Chinto quizá sería mejor elección para Amparo, esta, enfurecida, zanja el tema tajantemente.

Cuando vuelven las compañeras a seguir trabajando y le piden a Amparo que prosiga con su lectura, se le nota afectada por la conversación reciente con Ana. Lee con desgana, tanto es así, que alguna compañera empieza a cuestionar el contenido de los artículos, poniendo en evidencia su falta de fundamento intelectual y obligándola a esquivar las preguntas. Sin embargo, pronto recobra su alegría e ímpetu característicos y en una fulgurante aria en estilo tarantela (Es mi predia eterna) se vuelve a ganar los ánimos de las compañeras, que la aplauden entusiasmadamente.

Irrumpe un grupo de empleados de la fábrica, acompañados por una fanfarria de trompetas, anunciando la pronta llegada de los Delegados de Cantabria, que vienen a constituir la Unión del Norte. Las cigarreras, dispuestas a recibirlos con todos los honores, eligen a Amparo como su representante. En un estrepitoso final con el coro completo triunfante, suena el himno a la libertad: - ;Viva la Federal! ; Viva la libertad!

\section{Acto I, Esc. $2^{\mathrm{a}}$}

Exterior del salón de "El Círculo Rojo", el lugar donde se va a celebrar el encuentro con los representantes cántabros. El local está oculto por multitud de gente con pancartas, paraguas, etc. Mientras los delegados de la Unión del Norte preparan su reunión, la gente se congrega en las calles, bien para darles apoyo, bien por pura curiosidad, como es el caso de Baltasar y Borrel, quienes están paseando con la señora de García y sus hijas. Lejos de compartir el entusiasmo de las masas, expresan sus reticencias y preocupaciones sobre los eventos recientes que vienen a poner en entredicho su situación privilegiada, con unos pocos diálogos recitados sobre un fondo musical que refleja el estruendo en las calles, diálogos que nos hacen ver lo poco fundadas que son las opiniones políticas, incluso en las clases sociales acomodadas.

Baltasar le confiesa a Borrel su amor por Amparo, elogiándola por encima de las muchachas de alta escuela, pero al mismo tiempo advirtiendo que aún no ha sucedido nada, apenas un par de miradas... 
Aparece en escena Amparo, seguida de un grupo de cigarreras. Viene vestida con traje de percal claro y pañolón de Manila, de un rojo vivo. En su mano trae un ramo de rosas rojas con cintas doradas. Suenan una serie de himnos asociados a los movimientos revolucionarios: la Marsellesa, el Himno de Garibaldi y el Himno de Riego. Para tal efecto, sonará una pequeña banda desde el retropalco, que se puede formar con los propios músicos de la orquesta, que no sean requeridos en el foso en ese momento.

La muchedumbre se separa y deja ver el interior del Círculo Rojo... Es el gran momento de Amparo: Ella se presenta ante el presidente de la Unión, y entrega un discurso lleno de fervor (Balada: Soñaba, ilusionada), en el que relata un sueño suyo, en el cual se hace cómplice de un viejo héroe que le solicita ayuda ante el acoso de la policía, dándole cobijo y unas monedas ahorradas, aparte de ayudarle a repartir sus panfletos revolucionarios. Es el momento culminante del primer acto. La muchedumbre aclama a Amparo y sus nobles intenciones, en una intervención emotiva con coro doble (dos bandos a los lados del escenario que se van pasando la iniciativa del discurso).

Amparo, seguida de unas compañeras, se acerca, temblorosa al presidente. Está muy emocionada. Le ofrece el ramo de rosas, asegurándole la fidelidad de su colectivo (Nuestros corazones), ahondando más aún en su vasto repertorio de frases revolucionarias. Ante el aplauso general de los asistentes, el presidente asombrado la llama a su lado y le dedica personalmente un discurso (Acércate jovenzuela) que la eleva al papel de líder y heroína, mistificando su persona incluso con una alusión a la Torre de Hércules, símbolo de la ciudad y su defensa. Es aquí donde Amparo recibe el apodo "La Tribuna". La gente emocionada exclama su tributo a Amparo: -Que bello nombre, / Amparo, eres la Tribuna del pueblo.

\section{ACTO //}

El segundo acto contrasta con el primero y el tercero, en que se aleja un poco de lo que es el entramado político y ahonda en aspectos folclóricos y personales de los protagonistas. Se celebran festividades locales y religiosas que forman parte importantísima de la vida del pueblo y que constituyen un notable contraste con las intenciones revolucionarias manifestadas por la misma gente en el acto anterior. Es este acto el que eleva el relato de simple novela política a nivel de verdadero retrato sociológico de aquellos tiempos tan convulsos. Es aquí donde se materializa la relación amorosa entre Baltasar y Amparo, y finaliza este acto exactamente con el desenlace desilusionante de esa relación. Así, en este acto, no aparece la Fábrica de Tabacos, si no un chiringuito humilde, ambientándonos en un entorno en las afueras de la ciudad.

\section{Acto II, Esc. 1 ${ }^{\text {a }}$}

En la primera escena [el chiringuito] estará decorado con motivos propios de la fiesta de la Candelaria, patrona de las cigarreras y que se celebra durante el mes de febrero. Cerca del chiringuito hay un pequeño altar donde se encuentra una imagen de la Virgen adornada con profusión de mimosas. En escena Amparo, Ana y varias operarias están decorando el altar y el porche del chiringuito. Mientras decoran el altar, las muchachas intercambian 
rumores sobre el movimiento protestante (El mundo está perdido), descalificándolo tajantemente como pecado escandaloso. Al mismo tiempo, invocan a la Virgen de la Candelaria.

Entra Chinto con un gran paquete de guirnaldas, y a pesar de verse instantáneamente acosado por Amparo le declara su amor incondicional desde el primer día que la vio, confesándole la miseria en la que se encuentra (Se me hacían, dos palabritas). Ante el desprecio tajante de Amparo, Ana interviene llena de enfado, recordándole su humilde proveniencia y la grandilocuencia de sus pretensiones amorosas con Baltasar.

Entra la procesión de la Virgen de la Candelaria, con un sacerdote bendiciendo las velas expuestas en el altar. Aparecen Baltasar y Borrel, con este lamentándose sobre religión y política, que - según él - no hacen más que crear confusión. Baltasar no le hace caso y sólo se fija en Amparo, manifestando su creciente apetito de fumador por la moza. Se acercan los dos a Amparo y Ana, quedándose los cuatro solos, a medida que se retira la procesión.

Ana, que trajo merienda para todos, se pone a coquetear con Borrel (En la procesión no (e vi), permitiendo de esta manera que Amparo y Baltasar puedan entretenerse. Tras una conversación ligera, y animada por el vino, le pide a Borrel que le haga el molinillo, cosa que él hace - haciéndola girar cogida de las manos, sobre un fondo sinfónico animado - y que sale mal, ya que Ana aguanta la botella en la mano y se mancha toda de vino. Queda la sospecha de que lo puede haber hecho a propósito, ya que de esta manera tiene que retirarse a cambiarse, apelando así al caballerismo de Borrel, que se ve obligado a acompañarla... y dejando de este modo a Amparo y Baltasar a solas.

Amparo hace ademanes de querer retirarse también, pero es la gran oportunidad de Baltasar, que este no va a desaprovechar. Normalmente de carácter más bien reservado, se envalentona y se declara a Amparo, que inicialmente parece resistirse (Usted... / Quiere comprometerme). Pero resulta que las objeciones son más bien de carácter retórico, ya que ante la insistencia de Baltasar y sus repetidos juramentos forzados por Amparo (incluso llega a jurar con cierta reticencia Delante de la cara de Dios), esta sucumbe a su pasión amorosa, y ambos desaparecen besándose hacia el piso superior del chiringuito.

\section{Acto II, Esc. $2^{\underline{a}}$}

Esta escena se desarrolla en el mismo chiringuito de la escena anterior, pero ... a finales de mayo, unos tres meses después. Las cigarreras están celebrando una comida. Han terminado el yantar y animadas por el vino y la abundante comida están cantando. Es un bonito ejemplo de inclusión de una escena popular que - sin tener importancia en el hilo dramático - nos sitúa en el ambiente y constituye un testimonio valioso de las costumbres de la época. A pesar de que la novela original (y la ópera) esté redactada en castellano, Emilia Pardo Bazán reproduce una canción popular en gallego, esa lengua que tan poética y cantable es, y que tan ligada está al alma de su población. Parece citar una canción popular existente, pero al faltar más referencias sobre la melodía en cuestión, el compositor compuso un verdadero baile gallego (Válgame Dios), en estilo Muiñeira, que seguramente contará entre las escenas corales más populares y reconocibles de la ópera. 
$\mathrm{Al}$ aparecer dos pastores protestantes repartiendo folletos de la verdadera iglesia de Jesús, las cigarreras - recelosas y beligerantes - se burlan de ellos y los rechazan violentamente. Sobre un fondo musical en estilo Habanera (Me gusta el gallo), se desarrolla una escena que oscila entre graciosa y grotesca, dejando al descubierto las ingenuidades y flaquezas intelectuales de ambos lados y acabando en una estrepitosa huida de los pastores, que se ven en minoría. Quedan solas Amparo y Ana, y sale el tema de la relación amorosa con Baltasar. Ana la provoca en tono amistoso con que la infeliz ya estará pensando en próximo matrimonio, tachándola de soñadora, a lo cual Amparo contesta con una gran aria ( $A$ cada pitillo), describiendo en imágenes vívidas su sueño de un futuro feliz junta a Baltasar, en el que efectivamente se ve elevada a Señora, pero en el que no será altanera como otras y en el que abrirá las puertas de su hogar a sus amigas de ayer. Ana no comparte sus esperanzas, y acaban cantando en dúo un gran lamento por la miseria de las probes de este mundo. Amparo le confiesa que está esperando un bebé, pero le pide que lo mantenga en secreto, ya que Baltasar aún no lo sabe.

Entra Baltasar, y se deprime el ambiente. Ante la evidencia de que este no trae buenas noticias, Ana se retira, dándole oportunidad de iniciar lo que será su ruptura con Amparo. El tiempo -y la música- parece detenerse, y Baltasar comienza su discurso muy entrecortado y enrarecido, declarándole a Amparo que a causa de sus obligaciones tendrá que espaciar sus encuentros amorosos. A partir de este momento, hasta el final de la escena se va acumulando tensión dramática y musical, que desembocará en un gran clímax, el punto de inflexión de la obra entera.

Amparo, perpleja, no se rinde, le exige fieldad y que cumpla su palabra de casarse con ella, a lo cual él reacciona primero con ingenuidad falsa, y luego con creciente grandilocuencia y hasta sarcasmo (Mujer... mujer). Al ver Amparo que sus ruegos no hacen más que empeorar la actitud de Baltasar, le da la vuelta a la situación (jBasta ya!), y en un ataque de furor lo condena, lo amenaza prácticamente a muerte y sale airada escupiéndole a sus pies. El tema musical que antes sonó de boca de Baltasar, y que oscilaba entre dulce y sarcástico, cobra un tono amenazante pronunciado por Amparo, trasmutado en un momento dramático y poderoso que cierra el segundo acto.

\section{ACTO ///}

Si hasta el segundo acto los eventos bien podrían haber sucedido en muchas óperas de repertorio, es el tercer acto el que hace La Tribuna tan noble y significante. Lejos de sucumbir ante su destino, y a pesar del estigma social que supone el embarazo indebido, Amparo recobra su ánimo luchador y vuelve a liderar las acciones de las cigarreras, con más energía si cabe. Aun así, no olvida del todo a Baltasar, y en un gesto desesperado, hace un último intento para volver a restablecer contacto con él.

\section{Acto III, Esc. $1^{\text {a }}$}

Es otoño. Ante la puerta de la Fábrica de Tabacos permanece Amparo sola, con Ana y demás cigarreras al fondo. El estado de gestación de Amparo es ya patente. Amparo le canta una nana cariñosa al bebé en su vientre, augurándole un futuro mejor. 
Una vez acabada la nana introspectiva y soñadora, se hace patente la crispación entre las cigarreras (Conjunto: Qué cuenta tan larga). Resulta que hace meses que no están recibiendo sus pagas, y están llegando al límite de su paciencia. Permanecen ante la fábrica, sin intención de entrar, reclamando que les paguen finalmente. Sale el capataz de la fábrica intrigado por el rumor y ante la beligerancia de las cigarreras, bajo el liderazgo decidido de Amparo, le indica a esta que entre a hablar con el patrón.

Mientras Amparo está dentro, las cigarreras manifiestan su pena por ella y su estado, y además intercambian rumores sobre Baltasar, que según la gente está cortejando a las hijas de García, ya que estas acaban de ganar un pleito importante sobre una gran fortuna. Lamentando la situación, suena el coro femenino entero con Ana de solista, denunciando en una marcha entre reivindicativa e irónica la miseria de los probes y el poder del dinero ( $A$ embolsarse el dinero).

Vuelve Amparo, y el fondo musical no presagia buenas nuevas. Suena una marcha un tanto lúgubre, tema que ya se había presentado en la obertura del prólogo: -Medio mes nos ofrecen- se lamenta Amparo, declarando que se negó a aceptar el trato y alentando a las compañeras a ser firmes. Todas empiezan a tapiar la puerta de entrada con piedras, en modo de barricada, entonando el himno a la libertad que tan alegremente habían cantado en la escena fabril del Acto I, con versos como: - iAnimo, nuestra Tribuna! / iCon ella, con ella...! No obstante, cuando un pilluelo callejero anuncia que se está acercando la tropa, se deshace el motín al instante, a pesar de los ruegos de Amparo de aguantar juntas, y queda esta, sola frente a la guardia..., encabezada por Baltasar. Una vez más se enfrentan los dos, Amparo le mira fijamente y escupe en el suelo.

\section{Acto III, Esc. $2^{\mathrm{a}}$}

Esta última escena es una joya en sí, en cuanto a la convergencia de factores dramáticos, psicológicos y simbólicos, que además se reflejan fielmente en la música. Durante el curso de la escena sonarán una variedad de motivos musicales expuestos anteriormente durante la ópera (como ya al final de la escena anterior sonó la marcha inicial de la obertura), creando así una sensación de cohesión y apoyando el desenlace dramatúrgico. El contraste entre la tragedia privada de Amparo y el éxito aparente de sus esfuerzos revolucionarios se reflejan en el decorado, que nos deja ver una habitación de la humilde casa de Amparo, como también la calle con farolas, representando los ámbitos privado y público. Suena una introducción instrumental de cuerdas que oscila entre patética y esperanzada, reflejando el estado de Amparo que está en su habitación, ya a punto de dar a luz, y aun así sentada ante una mesa leyendo unos panfletos. Ante los dolores del inminente parto, se lamenta: -iCalla, hijo!, y en un monólogo, en el que a pesar del aparente éxito del movimiento revolucionario no puede esconder su amargura personal, le promete a su hijo un futuro más justo y próspero.

Entran Chinto y Ana, y esta - ante el estado de Amparo - se va en seguida a llamar a la partera. En una escena de las más sobrecogedoras de la ópera (No gimas), Chinto -ya solo junto a Amparo- le vuelve a prometer su amor incondicional, y se ofrece a ejercer de 
padre del bebé que está por nacer. No cae en tierra fértil la propuesta, ya que Amparo la rechaza violentamente entre injurias y condenas, fingiendo tener la situación controlada.

Entra Ana con la partera, y comienza una escena propia de ópera buffa, debido a la personalidad de la partera, mal hablada y grosera, que por su talante y por cómo se comporta, ya debe llevar ejerciendo desde hace mucho tiempo. Le encomienda varios recados a Chinto, pidiéndole una serie de ingredientes que más bien dan la impresión de que va a hacer un buen caldo (le pide entre otras cosas una gallina, espliego y romero), además de demandar un buen trago de anís para ella misma y vino para Amparo. De paso, se mofa de sus colegas charlatanes de galenos (más jóvenes, se supone) y sus métodos.

Nos adentramos en lo que son los momentos más dramáticos de la escena final. Amparo, que desde la entrada de la partera se había callado, le grita a Chinto, en un momento de máxima tensión musical (Una manda te encomiendo), que antes de hacer los recados vaya a buscar a Baltasar y que le anuncie el nacimiento de su hijo, insistiendo mucho en que diga niño, no niña. Se ve que, a pesar de todo su rencor y sus resentimientos, aún alberga un mínimo de esperanza y cariño por Baltasar.

Ana le pregunta a la partera cómo está yendo el parto, y esta se lamenta de lo que tardan estas primerizas... En un baile grotesco, entre flautín piccolo y contrafagot, hace alardes de sus capacidades y su experiencia, presumiendo que a su edad aún sólo se le han muerto dos en las manos.

Cambia el foco de atención a la calle, donde comienzan a verse grupos de gente comentando excitados las nuevas que han Ilegado de la capital. Vuelve a sonar el himno a la libertad del Acto I, con dos coros alternando exclamaciones esperanzadas, sobre los recientes desenlaces políticos. Hasta los niños en la calle cantan:-Federal, federal, / Dulce federal..., sobre la melodía del villancico conocido Navidad, navidad, dulce navidad.

Vuelve Chinto de hacer sus recados, con noticias que en oídos de Amparo tienen que sonar tanto a gloria como a perdición. Por un lado, relata el bullicio en las calles a causa del desenlace victorioso de los esfuerzos revolucionarios (Muy caro me ha costado, oyéndose al mismo tiempo y entremezclado con su relato las declamaciones de la gente en la calle), por otro lado, no puede más que declararle a Amparo que Baltasar se fue para Madrid, con la hija de García, a la que le había dado palabra de matrimonio, noticia que para las pretensiones de Amparo significa la estocada final.

Aumenta el bullicio en las calles, Amparo da un alarido, y por fin exclama la partera que nació una niña. Este detalle, que difiere del original literario, donde efectivamente nace un niño, obtiene su justificación por la idiosincrasia del propio género operístico, ya que carga la escena aún más de contradicción y simbolismo: echa por tierra la última esperanza de Amparo de que fuera un niño (para atraer a Baltasar), y por otro lado simboliza el nacimiento de la República, utopía por la que luchó tan fervientemente.

Después de esta erupción dramática, la música se vuelve más amena y casi celestial, rindiendo tributo al nacimiento de la niña, a la que Ana toma en brazos dulcemente. Le canta una nana sobre la misma melodía que cantó Amparo al inicio del mismo acto, pero con un texto lleno de alegría y dulzor (Cuando suenen las campanas). 
Se ve interrumpida por un último gran esfuerzo de Amparo, que se incorpora y grita un monólogo medio delirando (;Ah, maldito!), mezclando exclamaciones injuriosas y políticas con invocaciones a la Madre mía del Amparo, y acabando ya sin fuerza con las palabras Justicia al pueb/o... antes de colapsar, de un modo que al espectador dejará incluso ante la duda de si falleció o sólo des-falleció.

Sin embargo, pronto se aclara que debe de tratarse de un simple desmayo, ya que Ana no se inmuta y prosigue su nana, cantándole a la niña sus dulces palabras de felicidad. Cae el telón, mientras Ana eleva a la niña y la muchedumbre en la calle se aleja, entonando el himno victorioso: - jViva la libertad!

\title{
LA TRIBUNA
}

\author{
REPARTO: \\ Amparo \\ Ana \\ Rosendo \\ Chinto \\ Baltasar \\ Borrel \\ Presidente \\ Cuatro operarias \\ Obrero \\ Señora García e hijas \\ Sacerdote \\ Pastor $1 / 2$ \\ Capataz \\ Cigarreras $1 / 2 / 3$ \\ Partera \\ Coros Femenino, Masculino y Niños
}

\section{PRÓLOGO}

La escena representa la fachada principal de la Fábrica de Tabacos de Marineda. Ante la verja de hierro de la puerta principal están Chinto, vendiendo barquillos, y Rosendo, padre de Amparo. Paseantes, dos amas de cría, niños, etc... La tarde, que amenaza lluvia, no invita al paseo.

CHINTO.- Barquillero,barquilleeeé!

Al rico barquillo de canela y limón.

¿Que vienen de La Habana!

Al rico barquillo de canela y limón.

ROSENDO.- ¡Ah desgraciado Chinto!

Mal negocio harás,

Eligiendo este lugar. 


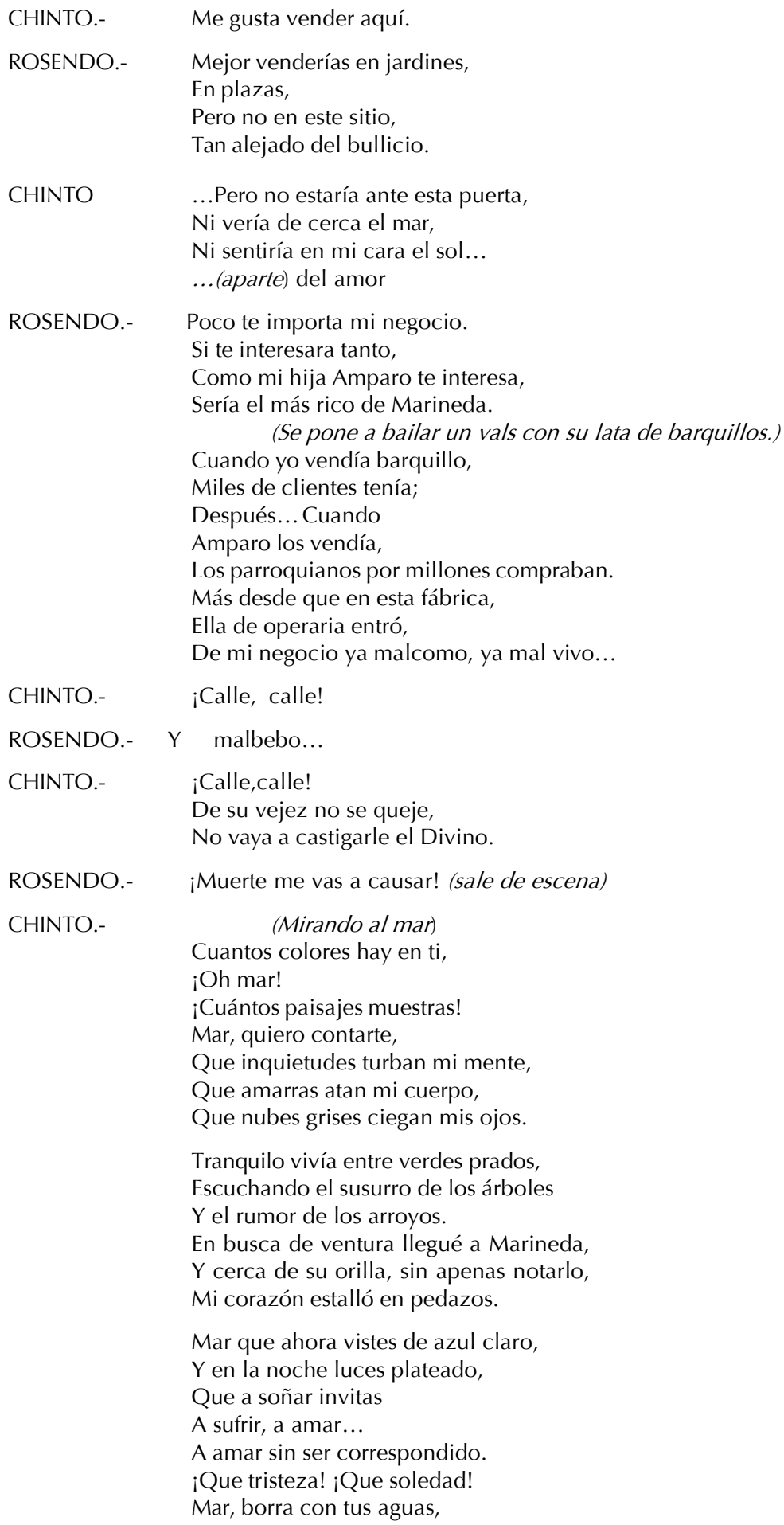


La burla y el desprecio

Que me ahogan. trabajan)

(Suena la sirena de la fábrica. Comienzan a salir las operarias que allí

¡Barquillero, barquilleeeé!

Al rico barquillo de canela y limón.

Que viene de La Habana.

(Se acerca Rosendo, que estaba sentado en un banco)

ROSENDO.- ¿Aun aquí? ¿Qué llevas en la bolsa?

CHINTO.- Unos melocotones.

ROSENDO.- $\quad$ ¡Mucho dinero, Chinto, gastas!

(Comienzan a salir las empleadas de la Fábrica de Tabacos. Las esperan sus amigos, novios. Entran en escena Baltasar y su amigo Borrel.)

CHINTO.- $\quad$ No son para mí.

ROSENDO.- $\quad$ Aun, peor me lo pones.

¡Aun peor!

¿Acaso crees, ingenuo,

Que los regalos abren corazones?

CHINTO.- $\quad$ Sé que no son llaves, pero...

(En la puerta de la fábrica aparecen Amparo y su amiga Ana. Amparo se hace la distraída para no encontrarse con Chinto.)

ANA.-

(Aludiendo a Chinto)

Puntual te espera.

AMPARO.- $\quad$ Ese zopenco.

ANA.-

Como todas las tardes,

Llueva o abrase.

AMPARO.- $\quad \mathrm{Ni}$ a sol ni asombra

Me deja.

ANA.- $\quad$ No es mala escolta.

AMPARO.- $\quad$ Calla, desgraciada.

(Se centra la escena en Baltasar y Borre)

BORREL.- ¿La has visto?

BALTASAR.- ¿ ¿A quién?

BORREL.- $\quad$ A la cigarrera,

A la hija del barquillero.

(Se pone a imitar el vals de Rosendo.)

BALTASAR.- ¿ ¿Cuál? ¿A esa que espera?

BORREL.- $\quad \mathrm{Si}$, hombre, esa,

(Mirándola)

Digna pieza para tan gran cazador.

BALTASAR.- $\quad$ Bella es en verdad. 
(Amparo y Ana delante del escenario. Chinto se acerca a ellas ofreciéndoles un melocotón. Baltasar se aproxima al grupo. Amparo mira con desprecio a Chinto. Toma el melocotón y se lo tira a Baltasar que lo atrapa. Se quedan mirándose fijamente).

\section{ACTO $1^{\circ}$ - ESCENA 1}

Interior de la Fábrica de Tabacos. Un grupo de operarias está trabajando en la confección del tabaco. Entre ellas está Amparo, en el centro, leyéndoles un periódico.

$\begin{array}{ll}\text { AMPARO.- } & \text { Título: ¿Hasta cuándo? } \\ & \text { Leo: } \\ & \text { Tomamos la pluma } \\ & \text { Trémulos de indignación, } \\ & \text { Para denunciar, } \\ & \text { Ante el resignado pueblo, } \\ & \text { Una nueva injusticia, } \\ & \text { Del indigno gobierno } \\ & \text { Que todavía aguantamos. }\end{array}$

(Murmullos de aprobación de las operarias)

OPERARIA NUEVA.- $\quad$ (En un aparte)

¿Quién es esa?

¿Por qué lee?

ANA.- $\quad$ Amparo, la lectora.

Las compañeras, de acuerdo,

Le abonamos el tiempo perdido.

Ella nos informará

De lo que pasa en cada día.

De joven era lectora,

En una afamada peluquería.

Su lengua es suelta, Robusto

su acento,

Fuerte su expresión

Y clara su dicción.

Calla, calla, escucha...

AMPARO.- $\quad$...la emoción ahoga nuestra voz,

La vergüenza enrojece nuestra faz,

Y si no bastan las palabras,

Recurramos a las armas y

Derramemos hasta la última gota

De nuestra sangre.

TODAS.- $\quad$ ¡Oh! ¡Muerte a los asesinos!

¡Viva la Federal!

¡Viva la libertad!

OPERARIA 1.- $\quad$ Ahora éste.

TODAS.- $\quad$ Amparo, lee, infórmanos, Abre nuestros ojos, cuéntanos.

AMPARO.(Leyendo)

"Acontecimiento incalificable". 
TODAS.- $\quad$ Oíd, callad.

Silencio, charlatanas.

AMPARO.- "Acontecimiento Incalificable"

Se nos asegura, que hará dos días,

Tres guardias civiles,

Francos de servicio,

En el café de la Aurora entraron,

Y un oficial que allí había,

Les arrestó...

TODAS.- ¿ ¿Sólo por entrar en un café?

Y se dice que hay "libertá".

AMPARO.- $\quad$ Sólo por entrar en un café

Les arrestó...

TODAS.-

...oíd, callad, callad.

AMPARO.- $\quad$...y preguntándoles la causa,

De su entrada en el local,

Le respondieron que su objeto era,

Tomar café.

TODAS.- Natural, shisss,

Oíd, callad, callad.

AMPARO.- $\quad$ No obstante, fueron

Por tres días arrestados.

Personas bien informadas,

Aseguran que órdenes se han dado,

De prohibir la entrada,

A cafés y bares,

De gente no adepta al gobierno.

Tal es el caso del café de la Aurora.

TODAS.- ¿Qué vergüenza! ¡Qué gran villanía!

Abajo Prim, shiss.

Oíd, callad, callad.

AMPARO.- $\quad$ De ser cierto,

Un ataque constituye

A los sagrados derechos individuales,

Y a la también,

Industria libre y honrada

De los cafeteros.

TODAS.- $\quad$...jOh! ...de los pobres cafeteros.

Y resobra la razón.

¡Que infamia colosal!

Si hubiera libertad,

Más injusticias no habría.

¡Que infamia colosal!

AMPARO.-

(Blandiendo el periódico)

Cuando vendrá la Federal,

Para que finalicen estas infamias.

TODAS.-

(Rodeando a Amparo)

¡Viva la Federal! 
ANA.-

¡Viva la libertad! Si

hubiera libertad,

Más injusticias no habría.

¡Viva la libertad!

(Suena una sirena. Se comienzan a retirar todas las empleadas, quedándose solas Amparo y Ana)

AMPARO.-

Hora de almuerzo.

ANA.-

...y de olvido de derechos

AMPARO.-

(Deteniendo a Amparo)

Espera... siéntate,

Quiero platicar, quedémonos.

(Saca unos bocadillos de una servilleta. Mira fijamente a Amparo)

Vi esta mañana,

Fuego en tu mirada,

De pasiones embriagada.

Mi sangre se heló.

¿Qué pretendes, Amparo?

Aun oigo el latido de tu corazón.

Un peligroso juego has iniciado,

Tu destino creo has equivocado.

Amparo piensa...

El corazón no piensa,

Y no siempre engaña.

ANA.- $\quad$ Dos mundos diferentes, Imposibles son de unir.

Noche y día,

Cielo e infierno,

Mundos diferentes son.

(Ambas a dúo)

AMPARO.- $\quad$...anochecer,

...purgatorio seré,

...unidos por el amor.

(Comienzan a entrar las cigarreras)

ANA.-

Tú aun tienes otro obsequiante,

Pero te callas.

AMPARO.- ¿QQuién, mujer?

ANA -

El barquillero Chinto;

Derretido está por Amparo.

AMPARO.- ¡Ese animal!

Parece una patata cruda,

Por favor...

TODAS.- $\quad$ Sigamos...

Trabajemos.

Lee, lee.

(Entregando el periódico a Amparo)

Callad, callad. 
AMPARO.-

(Con desgana recomienza a leer)

La situación está próxima,

A entrar en el ánimo,

Que desde el primer día,

La revolución debió emprender...

(Mientras lee, dos operarias comienzan a discutir)

OPERARIA 2.- ¿ ¿Quién te lo dijo,mujer?

OPERARIA 3.- $\quad$ Todo se sabe...

OPERARIA 2.- $\quad$ Pues estás fresca...

AMPARO.-

(sigue leyendo)

...los enemigos encubiertos

De la Republica Federal,

Acechando están al instante...

OPERARIA 1.- $\quad$ Y decidme, Amparo,

¿Qué significa la Federal?

ANA.-

Significa...

¿Qué ha de significar?, ¡repelo!

Lo que predican esos.

OPERARIA 1.- $\quad$ Pues no me hago cargo...

AMPARO.- $\quad$ Paque de Madrí,

El gobierno no se nos monte encima,

$\mathrm{Y}$ haya paz y trabajo y libertá.

TODAS.-

Eso, eso

(aplauden las palabras de Amparo)

Callad, callad.

Dejad escuchar.

AMPARO.- $\quad$ Es mi predia eterna,

Los peores, arriba, arriba,

Y nosotros, los probiños,

Mucho menos que abajo,

Quien no lo vea, ciego es, ciego es,

TODAS.- $\quad$ Quien no lo vea,

Ciego es, ciego es.

AMPARO.- $\quad$ Y si pudiera ¡oh Dios!

Una gran escoba manejar,

Yo, pueblo soberano,

Barrería a gobernadores

A ministros y generales,

Y en su lugar pondría,

A los que mi tan republicana gana,

Nombrara. fábrica).

(Todas aplauden. Entran agitados un grupo de empleados de la

OBREROS.- $\quad$ Los Delegados de Cantabria,

Llegan el martes por mar.

De la Unión del Norte,

Harán una realidad. 


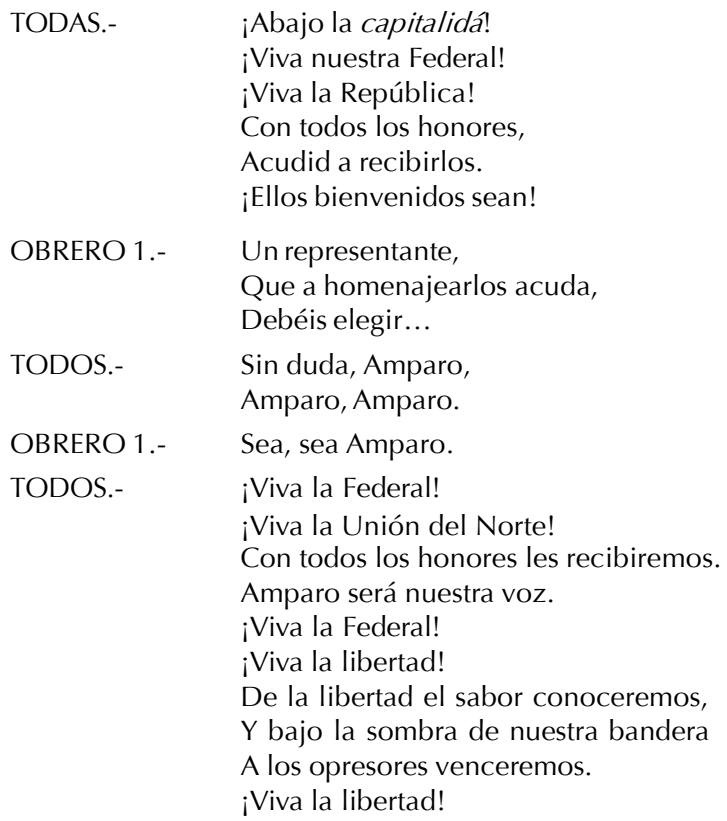

\section{ACTO $1^{\circ}$ - ESCENA II}

Exterior del salón de "El Círculo Rojo", el lugar donde se va a celebrar el encuentro con los representantes cántabros. El local está oculto por multitud de gente con pancartas, paraguas, etc., que en un momento determinado se separarán y dejarán ver el interior del salón, adornado con banderas rojas.

En la calle, entre la multitud, están Baltasar y Borrel con las de García (madre y dos hijas).

PUEBLO (coro masculino).-

Falta poco para el gran momento,

Su llegada al muelle

Ya anunciaron.

El barco, sin novedad,

En el muelle atracó.

Falta poco para su llegada,

La sala, luminosa, ya está preparada.

La Unión será una realidad.

SRA. GARCIA.- $\quad$ (con desprecio, mirando a la muchedumbre)

Animadito el paseo...

BORREL.- $\quad$ Animadísimo lo encuentro yo.

Los delegados de Cantabria,

Sin duda no tardarán.

SRA. GARCIA.- ¿Los delegados de qué?

BORREL.- $\quad$ La Unión del Norte viene afirmar.

SRA. GARCIA.- ¡Vaya una idea!

Huyo de esas confesiones. 
¡Que fastidio, Señor Borrel!

HIJA 1.- Nadie hay conocido.

SRA. GARCIA.- Vivas y mueras,

Abrazos y apretones de manos

Vergonzantes.

HIJA 2.-

El tío Isidro,

Dice,

Que si esto sigue así,

Dice,

Comercio e industria cerraran.

HIJA 1.- $\quad$ Y también iglesias quemarán.

HIJA 2.- No me gustan los alborotos,

Con tanta trifulca,

Los teatros están tan sosos...

HIJA 1.- La Sobrado dicen que es republicana.

SRA. GARCIA.- ¡Qué horror!

Cosa más cursi.

Paseen, niñas, paseen. escena)

(Baltasar y Borrel se quedan rezagados, mientras las García salen de

BORREL.-

(aludiendo a las niñas de García)

Entreténgalas, entreténgalas usted.

Pero, por otro lado,

Búsquese distracción,

No va usted a atarse,

A su edad.

BALTASAR.- $\quad$ Todo se sabe en esta ciudad,

Líos, historias, lances.

Pero hay una muchacha,

Sola en mi pensamiento,

Que si,

En verdad,

Me hace soñar.

BORREL.- ¿ ¿Una muchacha?

La de García no será.

BALTASAR.- $\quad$ No amigo, no.

Estos lances de alta escuela,

El suelo no ahuyentan.

Es...una cigarrera.

BORREL.- ¡Una cigarrera!

BALTASAR.- Pocos días hace,

Usted me la mostró,

De ella me habló.

La hija del barquillero.

BORREL.- $\quad$ Toma, toma.

El muy pícaro.

Esa mujer es una joya... 
BALTASAR.- $\quad$ Le advierto Borrel,

Que hasta el momento,

Nada ha sucedido.

Apenas un par de miradas...

BORREL.- $\quad$ Principio quieren las cosas...

(La multitud empieza a alborotarse. Aparece en escena Amparo, seguida de un grupo de cigarreras. Viene vestida con traje de percal claro y pañolón de Manila, de un rojo vivo. En su mano trae un ramo de rosas rojas con cintas doradas)

GENTE.- ¡YYa se aproximan!

¡Ya se acercan!

Inminente es su llegada.

AMPAROY HOMBRES.-

¡Suenen los himnos!

¡La Marsellesa!

¡Himno de Garibaldi!

(Amparo)

¡Himno de Riego!

(Todos)

¡Viva la Unión!

¡Viva la libertad!

AMPARO.- ¡Y viva la Federal!

(Acordes del Himno de Riego)

BORREL.- ¿La ve usted?

Esta chica vale un Perú.

BALTASAR.- $\quad$ Y olé, ique guapa es!

BORREL.- Porqué se meterá en política.

BALTASAR.- $\quad$ Es una epidemia.

Desayunamos política,

Almorzamos política,

$Y$ en la noche,

Nos arrebata a las bellas,

Y cenamos política.

(Cesa el himno)

CIGARRERAS.- ¡Y viva la Federal!

(La muchedumbre se separa y deja ver el interior del Círculo Rojo, profusamente decorado, donde se celebra la recepción a los miembros de la Unión del Norte. En un estrado preside un anciano de barba blanca; a su alrededor los acompañantes cántabros, políticos locales, etc. Se reflejan las actitudes dispares acerca del porvenir de la Unión)

AMPARO.- ¡Nuestro sueño hecho realidad!

No son supuestas aventuras,

$\mathrm{Ni}$ heroicidades soñadas, $\mathrm{Ni}$

sacrificios consumados.

Soñaba, ilusionada,

Que a mi puerta llamaba, Una

noche lluviosa y sombría, 
Un viejo héroe.

"Me persiguen", decía,

"ayudadme, socorredme,

La policía me acosa".

Y yo, compasiva,

En mi estancia lo escondía.

Más tarde,

Por recónditas callejuelas,

A seguro escondite lo guiaba.

Unas monedas ahorradas,

Le proporcionaba.

Un haz de proclamas recibía,

Para repartir al siguiente día.

"Si te cogen, ánima al cielo",

Sonriente me decía.

Con celo y sigilo las distribuía,

Y como recompensa de tanta fatiga,

Un apretón de manos frías,

Una mirada de gratitud,

Del fugitivo sólo esperaba...

TODOS.- ¡Esta chica es la libertad!

BANDO 1.- $\quad$ El primer paso se ha dado,

La firma ya se ha efectuado,

Cimiento inamovible será...

BANDO 2.- $\quad$ Mientras haya unidad.

¡Utópica realidad!

BANDO 1.- $\quad$ La Unión del Norte,

A la de España llevará...

BANDO 2.- $\quad$ Si eso no fuera soñar...

BANDO 1.- $\quad$ Y ejemplo del mundo entero será.

BANDO 2.- Utópica realidad.

PRESIDENTE.- $\quad$ Señores, sólo pido,

Amor, paz, fraternidad

BANDO 1.- $\quad$ La Unión del Norte,

A la de España llevará,

Y ejemplo del mundo entero será.

BANDO 2.- $\quad$ El camino arduo parece.

PRESIDENTE.- Tengamos confianza, señores,

La Unión Federal triunfará.

Juntos iniciemos la senda,

Y olvidemos la inquietud.

(Amparo, seguida de unas compañeras, se acerca, temblorosa al presidente. Está muy emocionada. Le ofrece el ramo de rosas)

OPERARIAS.- $\quad$ Señor presidente,

Emocionadas, Estas

modestas operarias, Humildes

y honradas cigarreras, Este

ramo le ofrecemos, 
En prueba de fidelidad

$Y$ para manifestar,

Nuestra devota adhesión

A la fraternal Unión.

AMPARO.- $\quad$ Nuestros corazones,

Laten animados,

Nuestra sangre,

Hierve avivada por la emoción.

Nuestra...nuestra garganta, Solo

un clamor sabe emitir:

¡Viva la Federal!

¡Viva la Libertad!

(Los asistentes aplauden el discurso de Amparo. El presidente la Ilama a su lado)

PRESIDENTE.- Acércate jovenzuela.

¡Que gran fuerza emanas.

Que hasta a duchos políticos, asombras!

Ven a mi lado y cuenta.

Se que eres cigarrera,

$Y$ que a tus compañeras lideras,

Que tuyos son sus problemas, $Y$

tuyos sus afanes,

Que su inorancia palias,

Y sus ojos abres.

Eres luz y faro,

Como el que esta ciudad guía,

Torre que de enemigos guarda,

Tribuna del pueblo,

Que enseñanzas acumulas.

Tribuna,

Este desde ahora será tu apodo.

¡Tribuna!

TODOS.- Que bello nombre,

Amparo, eres la Tribuna del pueblo.

Sé nuestro faro,

Tribuna, Sé

nuestra guía,

Tribuna,

Nuestra torre,

Tribuna, Amparo la Tribuna

AMPARO.-

(Muy emocionada)

¡Viva!

Viva usted... muchos años,

TODOS.- ¡Viva la Tribuna del pueblo!

¡Viva la Unión del Norte! 
Amparo, la Tribuna - Partitura - Acto I / Esc. $2^{\mathrm{a}}$

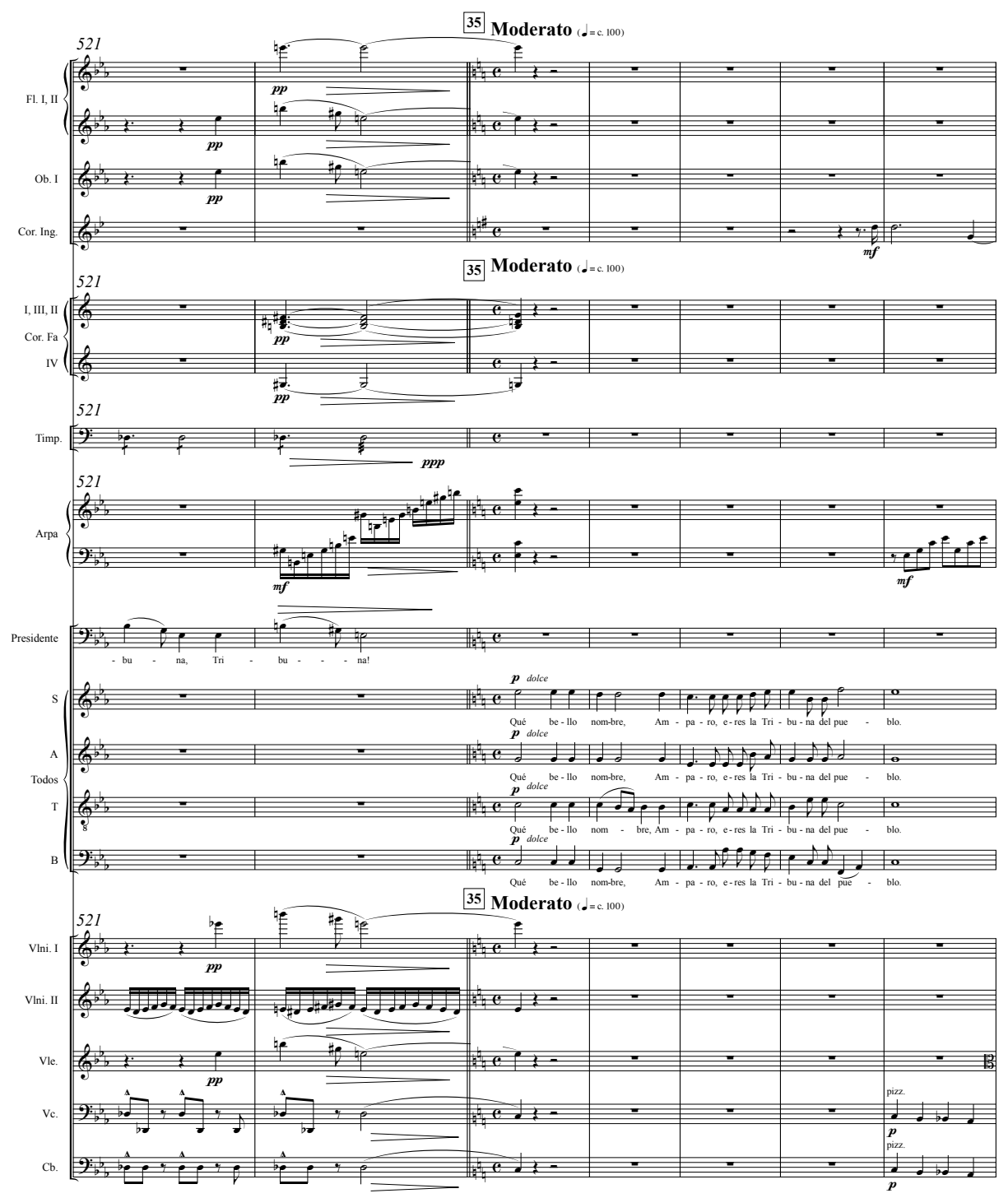




\section{ACTO $2^{\circ}$ - ESCENA I}

El escenario esta ocupado por un chiringuito, eje principal de las tres escenas en que se desarrolla el acto. En la primera escena estará decorado con motivos propios de la fiesta de la Candelaria, patrona de las cigarreras y que se celebra durante el mes de febrero. Cerca del chiringuito hay un pequeño altar donde se encuentra una imagen de la Virgen adornada con profusión de mimosas.

En escena Amparo, Ana y varias operarias están decorando el altar y el porche del chiringuito.

ANA.-

El mundo está perdido,

Un puro revoltijo.

¿Habéis oído,

Lo que en las Cortes pasó?

Un diputado de la Cataluña,

Dicen que dijo,

Que Dios no había,

$Y$ dicen que de la Virgen,

Que dijo esto y lo otro.

OPERARIAS.- ¿ ¿Y no le mataron?

¡Qué hombre mal hablado!

AMPARO.- ¡Lengua de escorpión!

OPERARIAS.- $\quad$ No habrá Dios para él, no.

ANA.- $\quad Y$ otra cosa hay,

Que mete aún más miedo.

Por esas capitales, dicen, Que

mala gente niños roba...

OPERARIAS.- $\quad$ Ángeles...

¿Para degollarlos?

ANA.- $\quad$ No mujer.

¡Son los protestantes!

AMPARO.- $\quad$ Una religión de allá,

De los inglis mang/is.

Que no rezan, sino cantan,

¡Y a sus clérigos casan!

OPERARIAS.- ¡jesús!

¡Qué escándalo!

¡Qué pecado!

¿Y el Arcebispo,

No los condena?

AMPARO.- Van contra el Arcebispo,

Contra los canónigos,

ANA.- $\quad Y$ contra el mismo Papa de Roma.

ANA.- $\quad Y$ contra Dios y contra los santos.

OPERARIAS.- $\quad Y$ hasta contra

La Virgen de la Candelaria,

...que hoy es su día,

...pongamos más mimosas,

...y más candelitas, 
De blanca cera,

Que hoy es un día de los más grandes,

Que fue cuando la Santa Virgen,

Su primer dolorito tuvo.

(Entra Chinto con un gran paquete de guirnaldas que entrega a una de las operarias. Estas lo recogen y se van a adornar el interior del chiringuito)

AMPARO.-

( $A$ Chinto, enojada)

¿A que entras con nosotras?

ANA.- $\quad$ Mujer,

Que operario ya es de la fábrica,

$\mathrm{Y}$ mismo derecho tiene que otros.

CHINTO.-

(Dirigiéndose a Amparo)

Se me hacían,

Dos palabritas.

AMPARO.- ¿ ¿Dos palabritas?

Más tengo que hacer,

Que tus tonterías oír.

CHINTO.- $\quad$ Lo que es tenerte voluntad,

Te tengo,

Desde el primer día que te vi,

Y me gustas más...

Que no se qué.

No pienso en otra cosa,

Que en tus quereres.

Y te quiero más...

Que no se qué.

Y me veo destruido,

Y el cuerpo,

No me quiere dormir.

(Amparo hace un gesto de desprecio)

ANA.- $\quad$ Mujer, no mohines.

¿No ves que te pide quereres?

AMPARO.- $\quad$ Si no te quitas de adelante,

Serás zopenco,

Repelo te voy a dar.

Hago de ti una desgracia.

¡Ay madre, que cruz!

(Chinto sale corriendo de escena)

ANA.- $\quad Y$ tú ¿qué eres?

Cigarrera como tu madre,

¿Y él qué era?

Barquillero como tu padre,

Y que mejor él ahora está.

Que por ahí digan,

Que eres graciosa,

Que a los hombres encandilas,

Y que si tal,

Y que si cual. 
Conversa y solo conversa.

El es bueno,

Y trabaja,

Pues a eso vamos,

Que a lo otro ipatarata!

( A lo lejos se oye la procesión de la Virgen de la Candelaria. Comienzan a entrar los mozos)

COROMOZOS.-

Como está escrito en la Ley del Señor,

Un par de tórtolas y dos palominos,

Ofrecieron por Él,

Como está escrito en la Ley del Señor.

SACERDOTEY CORO.-

Señor Padre,

Que de la nada todas las cosas creaste,

Y ordenaste que esta cera,

Por las abejas elaborada,

Para formar estos cirios sirviese,

Os rogamos,

Por intercesión de la Virgen de la Candelaria,

Cuya fiesta hoy celebramos,

Bendigáis estas candelas,

Para que sean luz de los hombres,

Y salud de sus cuerpos y almas,

Por mar y por tierra.

COROMOZOS.-

Como está escrito en la Ley del Señor,

Cumplidos los días de la Purificación,

Llevaron al Niño a Jerusalén,

Como está escrito en la Ley del Señor.

(Entran Baltasar y Borrel)

TODOS.- _ ¡Viva la Candelaria!

¡Viva nuestra patrona!

BORREL.- $\quad$ Tanta republica,

Y tanta oración,

Solo sirven para producir,

En la cabeza confusión.

BALTASAR.- $\quad$ (Llamando la atención sobre la figura de Amparo)

Calla... déjate de ripios... mírala.

Tan tierna y delicada,

Tan imperiosa y dominante.

Apetito de fumador,

La llamaría,

Que a toda costa aspira,

A consumir,

El más codiciado cigarro.

(Se acercan a Amparo y a Ana)

AMPARO.- $\quad$ Hoy se casan los pajaritos,

Día de la Candelaria... 
Hoy se casan...

(Baltasar la toma de la mano. Ana se acerca a una mesa del chiringuito con un atadillo en el que trae la merienda. Con la mira invita a Borrel. Poco a poco se irá retirando el coro quedando solo unas pocas parejas en el chiringuito. Ana está coqueteando con Borrel)

ANA.-

En la procesión no le vi.

BORREL.- No mujer,no,

Por quien soy,

Que no fui.

ANA.-

Pero ayer,

En la misa de San Andrés,

Bien que fue,

Que la García cantaba.

BORREL.- Mejorarla hasta una chicharra podría...

ANA.-

Pues por la oficialidad,

Ella dice

Que es muy alabada.

¿Cuántas ha cogido ya?

Goloso.

BORREL.- Mire,

Que hermosa esta fresa...

ANA.-

¡Larpeiro!

¡Ay!

Cuidado, Señor,

Que come un moscón.

(Siguen merendando. Ana, con una botella en la mano se levanta)

Hágame el molinillo. con el vino)

(Borrel la toma por las manos y juega con ella. Ana se moja el vestido

AMPARO.-

Hija mía, por Dios,

Como te has puesto,

Ven a mi casa

A por ropa seca.

ANA.-

No,

A la mía...

El cuerpo me pide cama.

AMPARO.- $\quad$ Toma mi mantón siquiera...

BORREL.- $\quad$ Espere Anita

Que yo la acompaño,

Puede ocurrirle a Usted algún revés.

ANA.-

¿Sabe qué venía pensando?

BORREL.- Diga Usted.

ANA.- $\quad$ Que es Usté... una alhaja... 
(Salen de escena. Amparo y Baltasar se quedan solos. A/ cabo de un instante, Amparo, tímidamente, intenta levantarse)

AMPARO.- Me voy a mi casa.

BALTASAR.- $\quad$ Amparo,

Ahora no,

No te marches,

Que estamos en el paraíso.

¿Por qué te escapas

Siempre de mi?

¿Acaso no sientes

Lo que yo siento?

Tan mal me tratas...

AMPARO.- $\quad$ ¿Usted que quiere que yo haga?

BALTASAR.- $\quad$ Que mejor te portes...

(Amparo se encara a Baltasar)

AMPARO.- $\quad$ Pues hablemos claro.

BALTASAR.- $\quad$ Di, hermosa, Amparo mía.

AMPARO.- $\quad$ Usted...

Quierecomprometerme,

Conducirse, Como

los demás se conducen, Con las

muchachas de mi esfera.

BALTASAR.- $\quad$ No, por cierto.

AMPARO.- $\quad$ Mire usted

Que bien sé,

Lo que en este mundo pasa.

Mucho hablar, y después....

Mi honor,

Es como el de cualquiera,

Soy hija del pueblo

¿Sabe Ustez?

Pero tengo mi altivez.

¿Comprende? La

sociedad se opondrá A

nuestra boda...

BALTASAR.- ¿Y porqué?

AMPARO.- $\quad$ ¡Y por qué!

BALTASAR.- $\quad$ No soy el primero,

$\mathrm{Ni}$ el segundo,

Que se casase con...

¡Hoy no hay clases sociales!

AMPARO.- $\quad$ Pero su familia,

Sus amigos,

¿Piensa que no desdeñarían, A

Amparo, la hija del pueblo?

BALTASAR.- ¡Qué importa eso!

Mi familia es una cosa,

Yo soy otra. 
Amparo, la Tribuna - Partitura - Acto II / Esc. $1^{\mathrm{a}}$
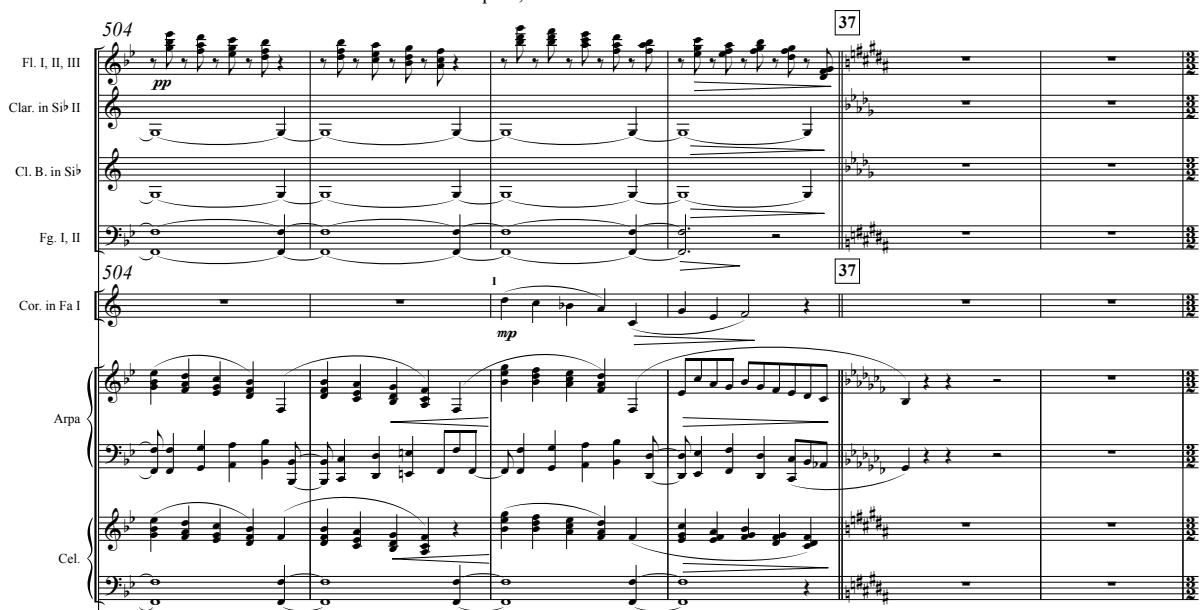

Amparo Baltasar 504

37
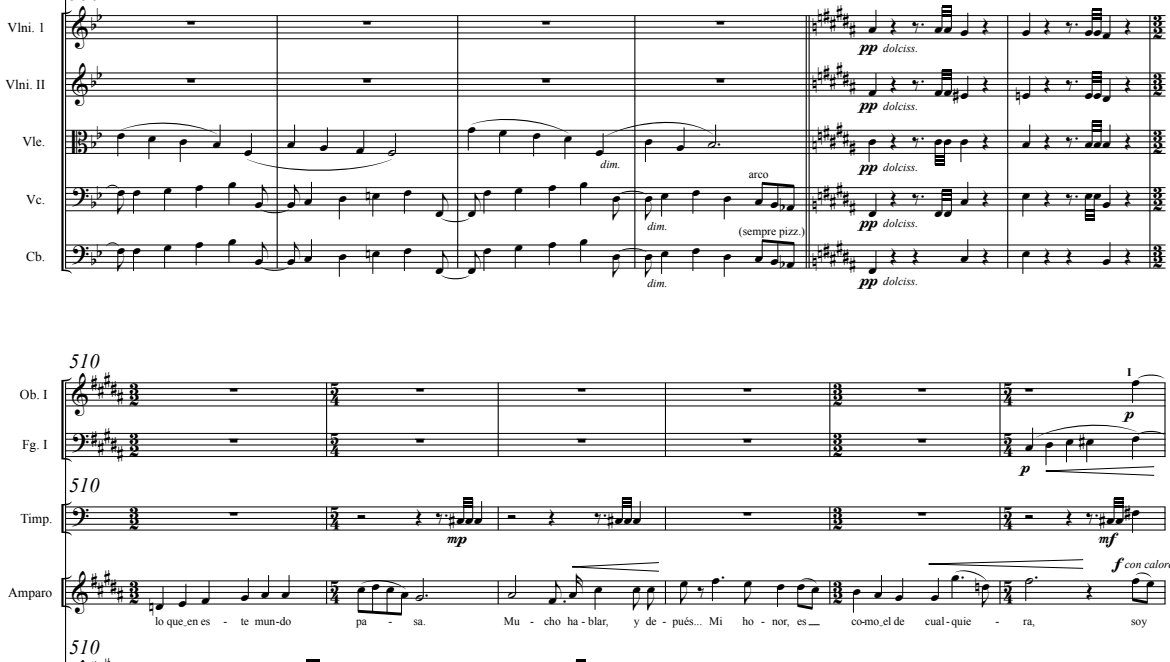

Vlni. 1 (1) Vlni. II (2) ve. ve. с. 


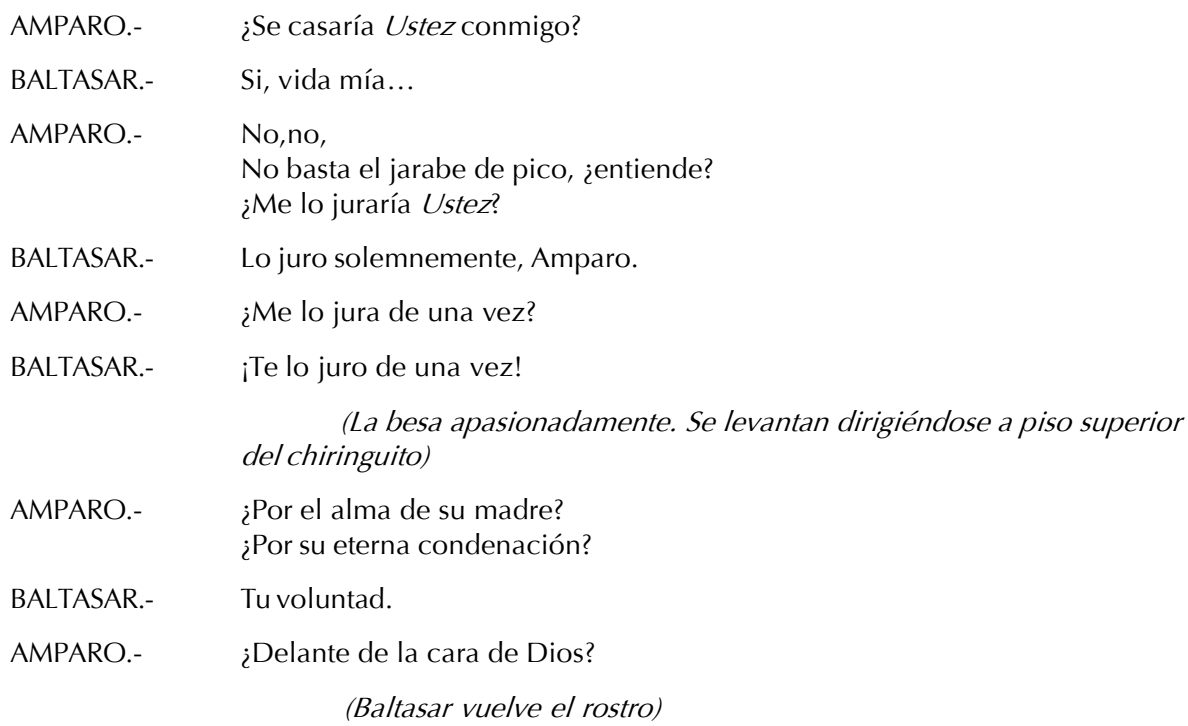

BALTASAR.- $\quad$ Si... si...

\section{ACTO $2^{\circ}$ - ESCENA II}

El mismo chiringuito de la escena anterior, pero la acción se desarrolla a finales del mes de mayo. Las cigarreras están celebrando una comida. Han terminado el yantar y animadas por el vino y la abundante comida están cantando.

CIGARRERAS.- Válgame Dios ;Ay de min!

$\mathrm{Qu}$ 'as probes das cigarreras,

Non ganan para zapatos

¡Por eso andan de chinelas!

S'a nosa Coruña está probe,

Non e por falta de diñeiro,

Que descubremos unha mina,

De xastres e zapateiros.

Válgame Dios,

Válgame Dios,

Ay de mi, ay de mí,

Que las probes, que las probes,

las cigarreras nos ganan ni para...

Válgame Dios,

Válgame Dios.

ANA.- $\quad$ Velay, lo que viene.

CIGARRERA.- De gabanón negro,

Que un mesmo cura parece.

ANA.- $\quad$ Cura no es,

Que patillas Ileva,

Como un padronés. 
AMPARO.- $\quad$ Es un "ínguilis",

Paíce que la barba

Pintaron con azafrán.

ANA.- $\quad$ ¿Y aquello qué es?

Un anteojo en un solo ojo,

Y colgado en el aire.

CIGARRERA.- Callad que vienen pa cá.

AMPARO.-

(Cantando)

Me gusta el gallo,

Me gusta el gallo,

Me gusta el gallo,

¡Con azafrán!

PASTOR 1.- $\quad$ A los pies de ustedes, señoras.

PASTOR 2.- $\quad$ Tengan la bondad,

Queridas señoras,

De aceptar estos folletos,

De la verdadera iglesia de Jesús

PASTOR 1.- $\quad$ (Repartiéndolos)

Cristo y Babilonia.

La Biblia revisada.

AMPARO.- $\quad$ ¡Oiga Ustez!

Esto que nos da,

No nos hace falta,

Ni lo queremos para nada.

Vaya a engañar a otras,

Que aquí bobas no semos.

PASTOR1.- Señora,

Que no es mi ánimo el ofenderla,

Solamente quiero iluminarlas,

Con la luz del Señor...

AMPARO.- $\quad$ Pensará, señor mister,

Que semos infelices, Que

por triste peseta, Comprar

pueden ustedes. Sepa

usted, señor mister,

¡Repelo! Que,

Ni por las minas del Potosí,

Renegamos, como Judas,

De Dios Jesús.

PASTOR 1 Y 2.- Señoras, hermanas nuestras,

Tómense ustedes,

La molestia de reflexionar,

$\mathrm{Y}$ de nuestras intenciones,

La pureza verán,

De darles a conocer,

La doctrina del Salvador.

AMPARO.- $\quad Y$ de su santa Madre,

Que de ella renegáis.

¡Pajarracos! 
ANA.-

AMPARO.-

TODAS.-

ANA.-

AMPARO.-

AMPARO.-

ANA.-

AMPARO.-
Pajarracos azafranados.

(Cogiendo los folletos y tirándolos al aire)

De parte de nuestra señora,

Paque no hagáis maldad.

Me gusta el gallo,

Me gusta el gallo,

Me gusta el gallo,

Con azafrán...

Darles pa/pelo,

Me gusta el gallo,

Me gusta el gallo....

(Quedan solas Amparo y Ana)

¿Quedas aquí?

Pensarás, infeliz,

En próximo matrimonio.

Y porqué, un suponer,

No se ha de casar con una.

No soy de la misma madera,

Que a otras ha sucedido.

Ya señora te ves...

Soñadora...

A cada pitillo que elaboro,

El suave crujido del papel,

Una esperanza dulce acompaña,

Que surge en mi corazón.

Cuando sea una señora,

No, no seré altanera como otras,

Que cuando arrastran sedas,

Miran por encima

A sus amigas de ayer.

Con afabilidad suma,

Las saludaré en la calle,

Enseñaré mi casa,

¡Mi hogar!

Con permiso del marido,

Una casa,

Con sillón de damasco carmesí,

Con consola de caoba,

Espejo dorado,

$\mathrm{Y}$ tantas, tantas, bujías encendidas.

¿Entiendes, Ana, mi soñar?

Esas cosas no tienen remedio,

Hacen ver lo blanco negro.

$Y$ de que sirve,

Ser una santa,

Si la gente no lo cree y estima.

AMPARO Y ANA.- Que han de hacer,

Las probes de este mundo, 
Sin tener a nadie,

Que por ellas mire...

Más que perderse,

Más que lamentarse.

ANA.- $\quad Y$ las consecuencias

De vuestra unión.

AMPARO.- $\quad$ Un secreto llevo en mi vientre...

ANA.-

¡Amparo!

AMPARO.- $\quad$ Silencio, por favor,

Es nuestro secreto.

ANA.- $\quad$ No lo sabe.

AMPARO.- $\quad$ A su tiempo.

Y calla, que ya viene ahí.

\section{(Entra Baltasar)}

BALTASAR.- $\quad$ Buenas tardes

ANA.-

Buenas nos la de Dios

(Aparte)

Buen talante no trae

(Amparo se acerca a él y le da unos cigarrillos. Baltasar lo enciende y comienza a fumar distraído. Ana, saliendo)

Quedad con Dios.

BALTASAR.- $\quad$ Muy devota se ha vuelto,

La pelona.

AMPARO.- $\quad$ ¡Baltasar!

(Baltasar queda en silencio, pensativo)

AMPARO.- $\quad$ No vienes muy alegre.

BALTASAR.- $\quad$ Trabajo tuve en volver,

Hay obligaciones que cumplir,

$\mathrm{Y}$ he de tener recato en nuestro trato.

A espaciar nuestras citas,

Me veo obligado.

AMPARO.- $\quad$ Ya son

Cada vez más dilatadas.

BALTASAR.- $\quad$ Tu compañía, sabes bien,

Me es muy grata,

Pero mis deberes,

Cada día son mayores.

(Amparo permanece callada, angustiada. Un largo silencio sucede. Amparo le toma de la mano, como si quisiera retenerlo)

Dicho esto, he de marcharme

Asuntos de servicio me reclaman.

(Amparo, resuelta, se levanta y se planta ante él)

AMPARO.- $\quad$ ¿Qué pretendes, Baltasar? 
¿Abandonarme?

Ahora, justo es,

Que cumplas tu palabra.

BALTASAR.- $\quad$ Ahora... la palabra.

AMPARO.- $\quad$ ¡De casarte conmigo!

Derecho creo, que tengo a pedir.

BALTASAR.- $\quad$ Mujer...mujer

No todas las cosas,

Salen a medida del deseo.

Pequeñas circunstancias,

El destino hacen cambiar,

Mi situación

Y mi familia

Me impiden venir,

Contra mi deseo.

AMPARO.- $\quad$ Tu familia... tu familia.

No decías que yo era una,

$Y$ ella era otra.

Tu linaje acaso mancho,

No eran mis padres honrados,

No me gano la vida dignamente,

Sin pedir nada a nadie.

¿Algo te he pedido?

No te fui siempre fiel...

BALTASAR.- $\quad$ No es eso mujer.

Lo que deseas,

Lo que deseamos,

Comprometernos es imposible.

BALTASARY AMPARO.-

Deja pasar el tiempo,

Que me asiente en la vida,

Que mi carrera se establezca,

Que sea independiente.

No comprometernos...

No comprometernos...

Pero tú te figuras,

Que soy tonta irepelo!

La comprometida, la engañada,

Soy yo jla Tribuna!

BALTASAR.- $\quad$ No llores, no grites.

AMPARO.- Habla claro.

¿Nos casamos?

BALTASAR.- $\quad$ Ya te lo he dicho,

Ahora no.

El tiempo lo dirá.

AMPARO.- $\quad$ ¿Y cuándo?

BALTASAR.- $\quad$ El tiempo lo dirá.

AMPARO.- $\quad$ ¡Basta ya! 
No quiero seguir escondida,

Ir a verte oculta,

En noches de frío.

Cualquier día verás,

Cuando te cruce por la calle,

Que de tu brazo me agarro,

Y canto, canto allí mismo,

Todo lo que pasa.

¿Entiendes, Falsario?

¿No tienes miedo a condenarte?

Pues si así mueres,

¡Fijo te condenas!

Y si viene la Federal,

En nombre de la Libertad,

¡Te mato!

Para que antes,

$\mathrm{Al}$ infierno vayas.

(Amparo le escupe a los pies y sale airada)

\section{ACTO $3^{\circ}$ - ESCENA I}

Es otoño. Ante la puerta de la Fábrica de Tabacos permanece Amparo sola, con Ana y demás cigarreras al fondo. El estado de gestación de Amparo es ya patente. Está sentada sobre una piedra en primer término. La luz la ilumina sólo a ella.

AMPARO.- $\quad$ Duerme mi dulce amor,

Espera a nacer.

Aguarda niño mío querido,

Aguarda a que salga el sol.

Cálido te abrigará,

Y te dará calor.

Espera mi niño,

Aguarda niño mío.

El ansiado tiempo de la luz

Tealumbrará

Y te enseñará el camino

De la felicidad.

Tu mísera cuna en trono

Se convertirá,

Y los pobres pañales

De seda vestirás.

Niño, espera, que tu madre

Te dé con amor su mano

$\mathrm{Y}$ te lleve por un camino

De justicia y felicidad.

Tu llegada

Las tinieblas disipará.

Aguarda mi niño,

Que poco falta ya.

ANA.-

Qué cuenta tan larga, 
Qué cuenta tan larga,

Darán a Dios,

Estas sanguijuelas.

CIGARRERAS.- $\quad$ Que nos chupan la sangre toda.

ANA.-

¡Qué justicia es ésta!

Unos trabajan la tierra,

$Y$ otros comen el trigo.

AMPARO.- Unos siembran y otros recogen.

Unos plantan la viña,

$\mathrm{Y}$ otros beben el vino.

ANA.- $\quad$ El que está debajo,

Debajito se queda.

AMPARO.- $\quad$ Lo que yo digo;

Hígados hay que tener,

Pa que nos quiten lo ganado.

CIGARRERAS.- Que ya lo tenemos ganado,

Y bien reganado,

Y bien trabajado.

AMPARO.- ¿ ¿No hacemos cigarros?

¿No cumplimos?

Que nos paguen lo nuestro.

¿No cumplimos?

ANA.- Que ya meses llevamos,

Sin ver ni un real.

CIGARRERAS.- $\quad$ Sin la paga,

No entramos,

No trabajamos.

AMPARO.- $\quad$ ¿Cigarreras no somos?

¿No cumplimos?

Que nos paguen lo nuestro.

¿No cumplimos?

ANA Y AMPARO.- Que ya meses llevamos,

Sin ver ni un real,

Sin ver un real.

TODAS.- $\quad$ Sin la paga, No

entramos, No

trabajamos.

(Sale el capataz de la fábrica)

CAPATAZ.- ¿Aquí qué sucede?

¿Qué significa este escándalo?

AMPARO.- $\quad$ Que hoy no se entra.

CIGARRERAS.- ¡Ea! No se trabaja,

Que no se entra.

ANA.-

Que hacen con nosotras

Iniquidás.

¡Y no aguantamos más! 
CIGARRERAS.- $\quad$ ¡Y no aguantamos más!

¡Sanguijuelas!

CAPATAZ.- $\quad$ Pero, ¿qué piden?

AMPARO.- $\quad$ jJusticia queremos!

CIGARRERAS.- Justicia y que nos paguen,

Que nos paguen lo nuestro.

CAPATAZ.- Vuelvan pronto al orden,

$\mathrm{Y}$ a la compostura.

No se entiende nada,

Hablen con más finura.

AMPARO.- $\quad$ No pedimos nada que no sea nuestro,

Estamos resueltas,

Resueltas, de verdad,

A exigir lo nuestro,

Y que abonen el jornal,

Ganado honrosamente, honrosamente

Con el sudor de nuestras frentes.

CIGARRERAS.- Sí, así se habla.

CAPATAZ.- Despejen el portal,

$\mathrm{O}$, a nuestro pesar,

Obligados nos veremos,

A llamar a la guardia.

TODAS.- $\quad$ La guardia, la guardia,

Que venga,

Que nos eche.

CAPATAZ.- $\quad$ Tú entra, Tribuna,

Y platica con el patrón,

Y vuestras quejas presenta.

(Entra Amparo. Las compañeras quedan comentando)

CIGARRERA 1.- Animosa sigue la probe,

Con lo que tiene que soportar.

CIGARRERA 2.- Que si alguna envidia excitaba, Ahora se volvió lástima.

CIGARRERA 3.- Dicen todos en la calle,

Que las García,

El gran pleito que tenían, Han ganado.

CIGARRERA 1.- Y ya toda la herencia, Han recuperao.

CIGARRERA 2.- $\quad$ Y el célebre Baltasarito...

CIGARRERA 3.- ... Detrás de ella anda, Las García.

TODAS.- $\quad$ A embolsarse el dinero,

Ciento y un mil duros.

Que belleza no hay,

Pero sí hermoso capital. 
CIGARRERA 1.- Si hubiese justicia...

ANA.- $\quad$ Ya se ve,

Justicia, hay de dos maneras,

Una, a rajatabla, pa los probes,

$\mathrm{Y}$ otra, de manga ancha,

Pa los que son ricos.

CIGARRERA 3.- Estos malditos de Dios,

Solo valen, repelo,

Paperder chicas buenas,

Chicas inocentes.

\section{(Vuelve Amparo)}

CIGARRERA 1.- Ahí viene Amparo,

Cuenta, ¿qué te dicen?

TODAS.- $\quad$ Cuenta, cuenta, Amparo.

¿Pagan o no pagan?

AMPARO.- $\quad$ Medio mes nos ofrecen,

Hasta la remisión de fondos,

¡Nos negamos señor!

Le dije,

Que a ustedes ná les falta,

Y a nosotros ni pa el pan

De nuestros hijos tenemos.

Amenazo me con la Guardia Real,

¡Que venga la guardia!

Le dije,

Que a las cigarreras,

Con la Tribuna al frente,

Se encontrarán.

ANA.- Hagamos barricada.

TODAS.- $\quad$ Cojamos piedras,

Tapiemos la puerta.

(Amparo toma un objeto de grandes dimensiones y con gran esfuerzo lo coloca delante de la puerta de acceso a la fábrica)

Mirad Amparo, la Tribuna,

Tan adelantada en meses,

Y como trajina.

Ella sola la piedra levanta.

¡Animo, nuestra Tribuna!

¡Con ella, con ella...!

¡Amparo, la Tribuna!

(Todas cogen piedras y cosa para levantar la barricada)

PILLUELO.- $\quad$ ¡Viene la tropa!

TODAS.-

(Con espanto)

¡Viene la tropa!

AMPARO. ¡No temáis,

No nos comerán! 
(Un pelotón de la guardia, con Baltasar al frente, se pone ante ella. Las cigarreras, asustadas, se retiran al fondo de la escena. Amparo se enfrenta firme ante Baltasar. Se dirige hacia él, le mira fijamente y escupe en el suelo)

\section{ACTO $3^{\circ}$ - ESCENA II}

La escena representa la humilde casa de Amparo; una amplia habitación que es cocina, sala y dormitorio. Rodeándola una calle con farolas. Amparo está sentada ante una mesa leyendo unos panfletos. Está ya con dolores del inminente parto.

AMPARO.-

¡Calla, hijo!

Ahora sí que llegó la nuestra.

Macarroni de una vez se va,

Luego deja a Pi y Margall.

Sal Amadeo de Madriz,

Que hoy llega la Federal,

Que la república se proclama ya.

¡Calla, hijo!

$$
\text { (Da un grito de dolor) }
$$

Que tus ojos injusticias no verán,

Y no tendrás,

En jamás, falta de pan.

¡Calla, hijo!

(Entran en escena Chinto y Ana)

AMPARO.- $\quad$ No me tengo... Piernas

tengo de trapo.

ANA.-

¿Qué sientes?, amiga.

AMPARO.- $\quad$ Siento frío, mucho frío...

Y sueño, mucho sueño,

Pero, al mismo tiempo,

Rabio por andar,

Por trajinar,

Por sollozar.

ANA.- $\quad$ Chinto, rápido, ve por la partera.

CHINTO.- ¿Por la partera?

AMPARO.- $\quad$ Calla, que vergüenza.

No la avises.

ANA.- $\quad$ Que remedio,

Si así sigues,

La partera es necesaria.

AMPARO.- $\quad$ ¡Infeliz de mí!

Que nunca yo naciera.

CHINTO.- $\quad$ ¿Por la partera?

ANA.- $\quad$ Queda tú,inútil,

Y vela por ella,

Que en un amén Jesús,

Volvemos. 
AMPARO.- $\quad$ ¡Ay mísera de mí!

CHINTO.- No gimas,

Que el corazón me partes.

Mujer, oye mujer del alma mía,

No te aflijas,

$\mathrm{Ni}$ te martirices.

Si lo deseas,

Si lo quieres,

Yo me pondré por padre,

Y si lo tienes a voluntad,

Nos casamos,

Y si no,

Lo que tú digas.

Que tu fiel Chinto,

No más que tu felicidad desea.

AMPARO.- $\quad$ ¡Sal de ahí, zopenco!

Que te mato.

¡Quieres condenarme?

Lo mío es mío.

¡Y de nadie más!

Lo mío es mío...

\section{(Entran Ana y la partera)}

PARTERA.- $\quad$ A las buenas tardes.

Veamos que hace falta...

(Mientras la consulta)

Aceite...un poco de aceite, rapaz.

ANA.-

¿Qué tal está?

PARTERA.- Bien, bien, mujer.

Aceite, iporretas!

$\mathrm{Y}$ unas gotitas de anís.

CHINTO.-

(Dándole el aceite)

¿Anís? Para que...

PARTERA.- $\quad$ Para mí, puñeta,

Que soy de Dios,

$Y$ vida me da un trago.

Y Vino, ¿hay vino por aquí?

CHINTO.- ¿ ¿Vino? ¿Pa Usted?

PARTERA.- Pa ella, canalla,

Que bien necesita ánimos,

La probe.

Piensas tú, que yo le doy,

Desos durmientes y calmantes,

Que dan esos charlatanes de galenos.

Fuerza es lo que hace falta,

Y el vino da fuerza.

También traerás,

De chocolate, tres onzas,

Y si con una gallina, 
Por el camino topas,

Le retuerces el cuello,

Y aquí la portas,

Pa un caldo hacer.

(Chinto va hacia la puerta)

Y un cabito de cera,

Y espliego y romero.

(Dirigiéndose a Ana)

Y tú aviva el fuego de la lumbre.

AMPARO.-

(Gritando a Chinto)

Una manda te encomiendo.

Atiende bien,

Antes de nada,

Al cuartel de infantería

Acudes presto, te ruego.

Si allí no ves a Baltasar,

A casa suya llégate,

Y le contarás,

Atiende bien el encargo,

Le dirás que un niño he tenido.

CHINTO.-

¿Un niño?

AMPARO.- $\quad$ ¡Un niño!

No sea que digas niña.

Un niño, un niño.

CHINTO.- $\quad$ ¿No digo más?

AMPARO.- No, no digas más!

(Chinto sale)

Él ya sabe lo que prometió

Y que si quiere aún

Ponerse de padre,

Hágase su voluntad.

(Aparte Ana conversa con la partera)

ANA.-

¿Y, cómo va?

PARTERA.- $\quad$ Tarda, porretas,

Tarda... Estas

primerizas...

Yo soy clara como el agua,

$\mathrm{Y}$ no se me murieron,

En la edad que tengo,

Más de dos en las manos.

Yo cuanto puedo, hago, $Y$

mil friegas y unturas,

Llevo dado.

(En la calle comienzan a verse grupos de gente comentando excitados las nuevas que han /legado de la capital)

GRUPO 1.- $\quad$ Dicen, que de Madrid, El de Saboya, 
Ya partió.

GRUPO 2.- $\quad$ Con el diablo vaya ya.

GRUPO 1.- Pi y Margall,

De inmediato,

Impondrá la federal.

GRUPO 2.- $\quad$ Para ripios estamos.

(Aparte)

TODOS.- La federal, la federal,

Esto no es más,

Según aseguran,

Que la anarquía organizar.

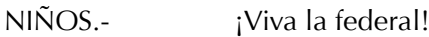

¡Viva la federal! UN

NIÑO.- ¿ ¿Y eso qué es?

OTRO NIÑO.- $\quad$ No sé...algo bueno,

Como la Navidad.

NIÑOS.-

(Imitando un villancico)

Federal, federal,

Dulce federal...

(Dentro de la casa)

ANA.- $\quad$ No se qué pasa,

Todos andan revueltos

(Entra Chinto, muy excitado)

CHINTO.- $\quad$ Muy caro me ha costado,

Revuelto todo está,

No se puede andar

Sin tropezar.

La gente corre

Como loca por las calles.

AMPARO/ANA.- ¡QQué dices, Chinto!

¿Será la cierta?

¿Y Baltasar?

GRUPO 1.- $\quad$ En Madrid ya hay república, Macarroni se ha pirado.

GRUPO 2.- $\quad$ Los bandos se están publicando,

Y con trapos de colores,

Los balcones están adornando.

Es el delirio...

CHINTO.- $\quad$ Pues fui al cuartel,

Y allí no estaba...

ANA.- Irías a su casa volando.

Y fui a su casa volando

CHINTO.- $\quad$ Allí fui,

Y no estaba... Que

pa la capital, Con

las de García, 
PARTERA.-

ANA.-

AMPARO.-

ANA.-

PUEBLO.-
Partido había.

Y que palabra de matrimonio,

A su hija había dado...

(En la calle cada vez se va aglomerando más gente, enarbolando banderas, flores, etc. Amparo da un alarido. Ana y la partera se inclinan hacia ella para ayudarla al parto. Mientras sigue la acción en la calle. A/ cabo de un momento las mujeres limpian a la niña recién nacida)

¡Es una niña!

(La toma en brazos dulcemente)

Cuando suenen las campanas,

Himnos de victoria,

Alégrate, tu corazón

De júbilo saltará.

Crece fuerte, dulce amor,

Por fin naciste ya.

Alégrate, mi dulce niña,

Hoy ha salido el sol...

¡Ah, maldito!

¡Justicia al pueblo!

¡Justicia!

¡Favor, Madre mía del Amparo!

¿Cómo consientes esto?

¡La palabra!

(Delirando)

Él me ha dado la palabra...

Los derechos...

Hay que matar a los oficiales.

A los oficiales, a los oficiales...

Él me ha dado la palabra...

Justicia al pueblo...

(Amparo colapsa.)

...Cálido te abrigará

Y te dará calor.

Disfruta de la luz, mi niña,

Alégrate, niña mía.

El ansiado tiempo de la luz

Tealumbrará

Y te ensañará el camino

De la felicidad.

(En la calle la gente pasa entonando himnos)

¡Viva la Republica!

¡Viva la Federal!

¡Viva la libertad!

(Se alejan la muchedumbre y los cantos. Ana coge en alto a la niña mientras cae el telón)

FIN DE LA ÓPERA 
Amparo, la Tribuna - Partitura - Acto III / Esc. $2^{a}$

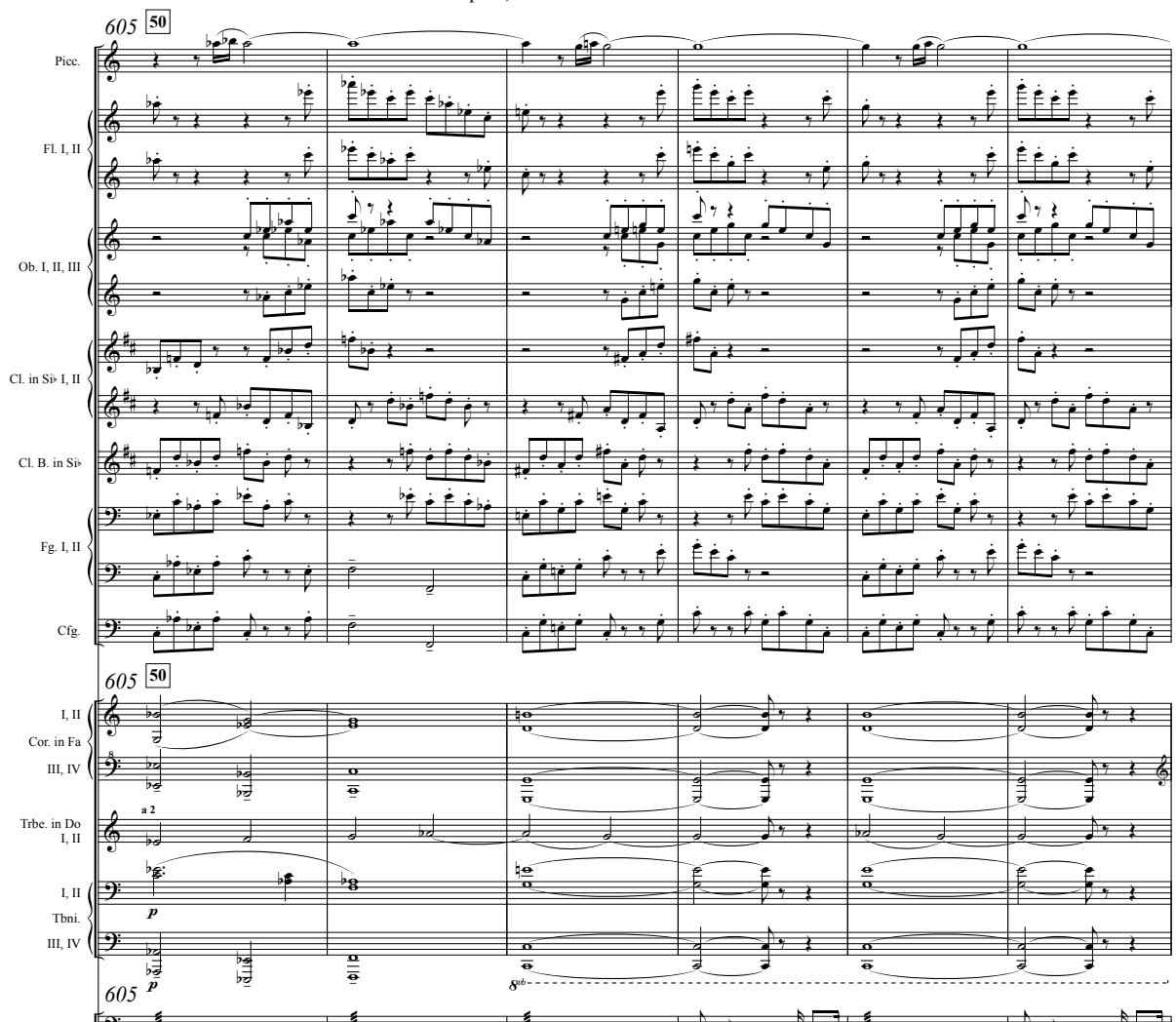

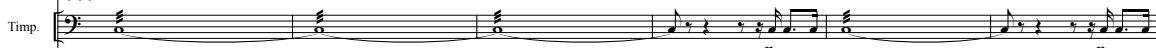

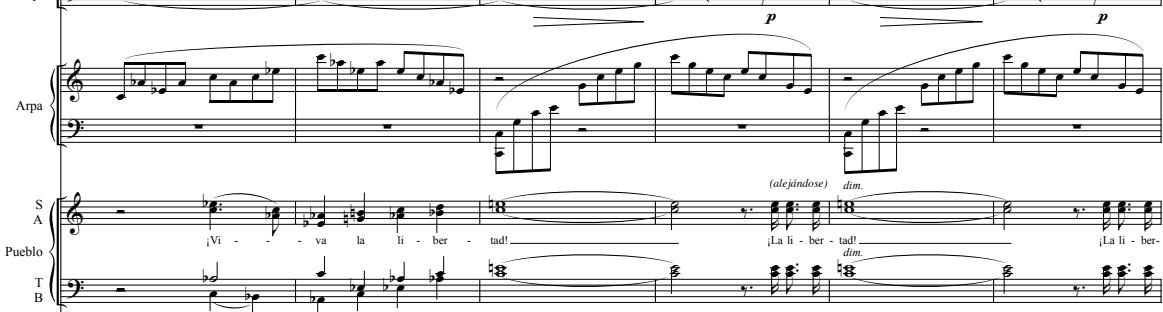

50

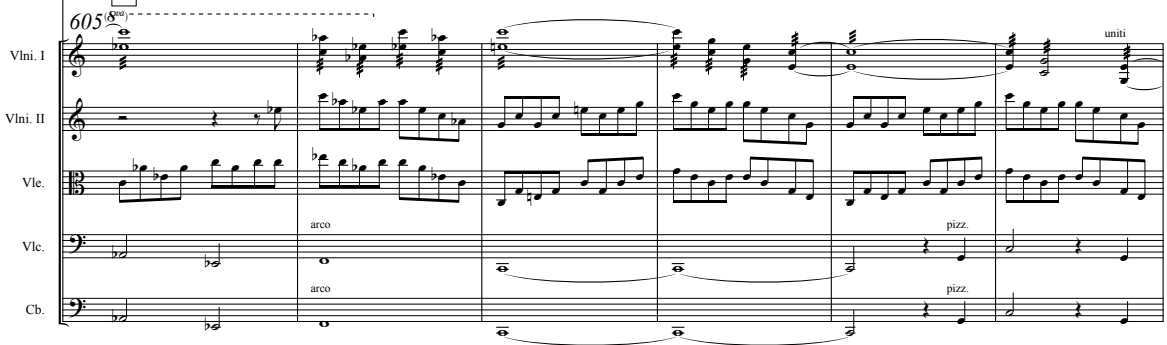


Amparo, la Tribuna - Partitura - Acto III / Esc. $2^{a}$
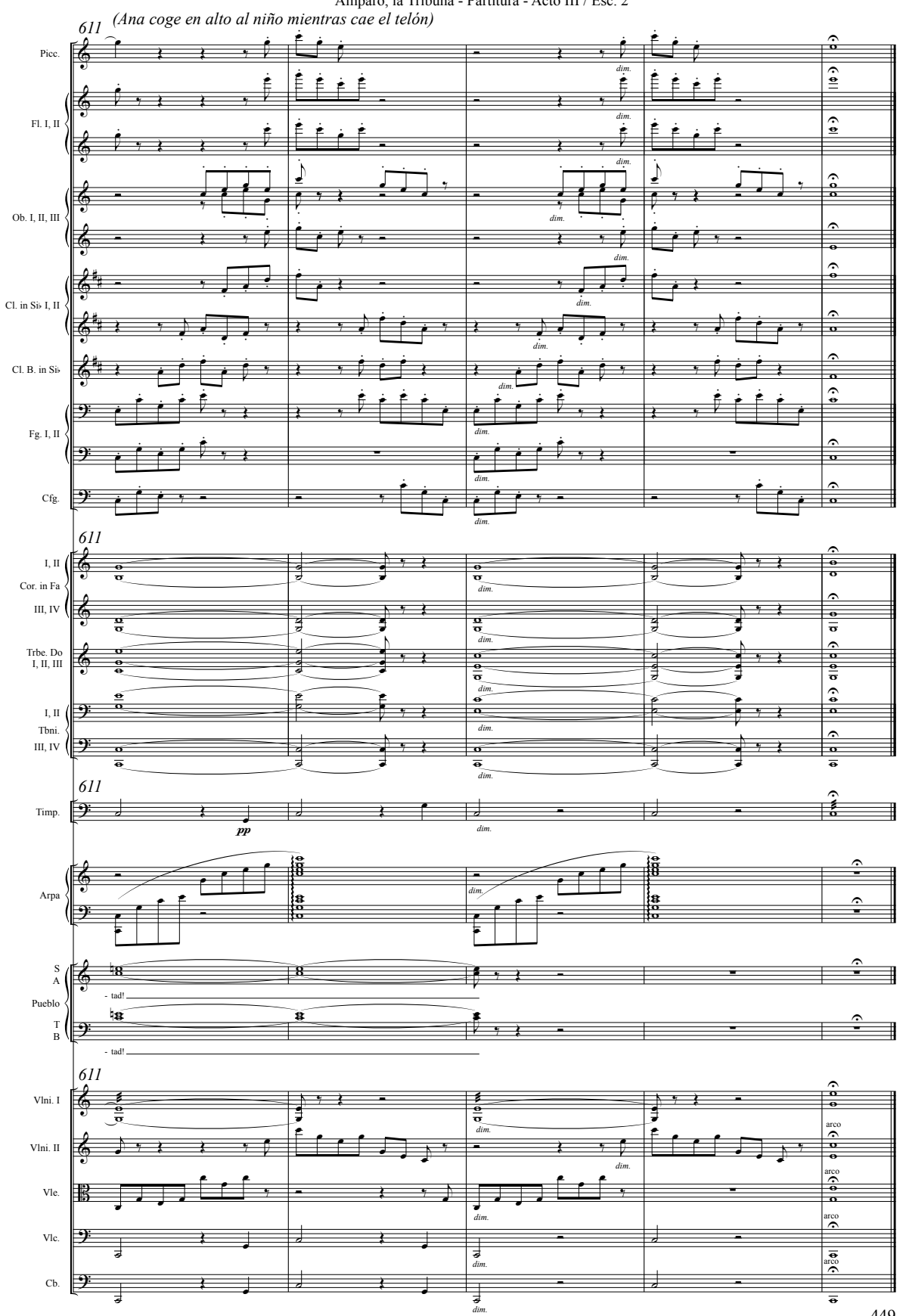